\title{
Postnatal development of morphological features and vocalization in the pomona leaf-nosed bat Hipposideros pomona
}

\author{
Long-ru Jin • Ai-qing Lin $\cdot$ Ke-ping Sun $\cdot$ Ying Liu • \\ Jiang Feng
}

Received: 24 January 2010 / Accepted: 8 July 2010 /Published online: 5 November 2010

(C) Mammal Research Institute, Polish Academy of Sciences, Białowieża, Poland 2010

\begin{abstract}
Based on mark-recapture data, we studied the postnatal development of morphological features and vocalization of the pomona leaf-nosed bat (Hipposideros pomona). Morphological changes indicated that body mass and length of forearm followed a linear pattern of growth until 13 days of age at mean growth rates of $0.14 \mathrm{~g} /$ day and $1.08 \mathrm{~mm} /$ day, respectively, and thereafter, growth rates slowed. The length of the total epiphyseal gap of the fourth metacarpal-phalangeal joint showed a linear increase for up to 10 days, followed by a linear decrease until day 40 at a mean rate of $0.09 \mathrm{~mm} /$ day. Together, two equations permitted estimation of the age of H. pomona pups between 1 and 40 days. The logistic equation provided the best fit to the empirical curves for body mass and length of forearm. Studies of vocal development showed that the precursors of echolocation calls were not emitted until day 7 after birth. As the pups grew, the dominant frequency (DF) of isolation calls increased and number of harmonics (NH) decreased, whereas the duration remained relatively stable. The DF and $\mathrm{BFM}_{2}$ (the bandwidth of the terminal frequencymodulated sweep from the second harmonic) of the early echolocation calls increased; however, the $\mathrm{NH}$ and duration decreased.
\end{abstract}

Communicated by: Karol Zub

L.-r. Jin· A.-q. Lin·K.-p. Sun · Y. Liu ·J. Feng

Jilin Key Laboratory of Animal Resource Conservation

and Utilization, Northeast Normal University,

Changchun 130024, China

L.-r. Jin · A.-q. Lin $\cdot$ K.-p. Sun $\cdot$ Y. Liu $\cdot$ J. Feng $(\bowtie)$

Key Laboratory for Wetland Ecology and Vegetation Restoration of National Environmental Protection,

Northeast Normal University,

Changchun 130024, China

e-mail: fengj@nenu.edu.cn
Keywords Body mass $\cdot$ Echolocation calls $\cdot$ Epiphyseal gap $\cdot$ Length of forearm $\cdot$ Hipposideros pomona $\cdot$ Isolation calls

\section{Introduction}

Most insectivorous bats are altricial, and their young experience a postnatal growth period in which they develop appropriate sensory and locomotor skills to become independent from their mothers (Baptista et al. 2000). Many researchers have studied this period with respect to changes in behavior, physiology, and ecology to investigate life history stages and to estimate maternal investment (Kunz et al. 2009). There have been numerous studies on postnatal development of bats under both natural (e.g., Gould 1971; Kunz and Robson 1995; Hoying and Kunz 1998; Chaverri and Kunz 2006; Liu et al. 2009) and captive conditions (e.g., Rajan and Marimuthu 1999; Elangovan et al. 2003; Vater et al. 2003; Zhang et al. 2005; reviewed in Kunz et al. 2009). These studies mainly focused on two aspects: morphological feature changes and vocal development.

Studies on morphological development have shown that body mass, length of forearm, and the length of the total epiphyseal gap of the fourth metacarpal-phalangeal joint as well as changes in tooth development can be used to estimate the age of young bats (Anthony 1988; BrunetRossinni and Wilkinson 2009). Accurate age determination is important for behavioral, physiological, and ecological studies. In the absence of age estimate, it is impossible to determine growth rates, the timing of sexual maturity, or the development of various behavioral repertoires of an animal (Elangovan et al. 2003; Frick et al. 2010). However, compared with length of forearm and the length of the total 
epiphyseal gap, body mass is not a good character for estimating age because of its sensitivity to nutritional intake, energy expenditure, and water flux (Kurta and Kunz 1987; Hoying and Kunz 1998; Stern and Kunz 1998; Kunz et al. 2009), but it is ideal for interspecific comparisons of growth rates throughout the postnatal growth period among species from different regions, although comparative studies should be based on the same model (Zullinger et al. 1984).

Studies focusing on the ontogeny of vocalizations in bats have shown that, shortly after birth, the vocal repertoire of an infant bat differs from that of an adult (Brown et al. 1983; Jones et al. 1991; Moss et al. 1997; Vater et al. 2003; Zhang et al. 2005). Generally, the vocal repertoire of an infant can be divided into two types of calls: isolation calls (mainly for communication) and early echolocation calls (mainly for echolocation). Both consist of multiple harmonics (Moss et al. 1997; Vater et al. 2003). Isolation calls normally concentrate the maximum energy on the first harmonic (Gould et al. 1973; Brown and Grinnell 1980; Knörnschild et al. 2007). However, early echolocation calls always contain the maximum energy in the same harmonic as echolocation calls of adults (Vater et al. 2003). In some species, early isolation calls of young bats may be precursors to echolocation calls (e.g., Myotis lucifugusMoss et al. 1997; Carollia perspicillata-Sterbing 2002). However, in other species, echolocation and isolation calls appear to have separate origins (Noctilio albiventris-Brown et al. 1983; Pteronotus parnellii-Vater et al. 2003). Additionally, as the infants grow, there is a general trend for isolation calls and early echolocation calls to rise in frequency, decrease in duration and number of harmonics, and become stereotyped (Jones et al. 1991; De Fanis and Jones 1995; Moss et al. 1997).

Most studies on postnatal development of bats have been conducted on members of the family Vespertilionidae, with few studies focusing on Hipposideridae, especially those species located in subtropical regions. The pomona leaf-nosed bat (Hipposideros pomona) is a widespread species, occurring through Bangladesh and India to Burma, Thailand, Laos, Cambodia, Vietnam, West Malaysia, and South China (Simmons 2005). To our knowledge, no published data are available on its postnatal development or on its vocal repertoire. In this study, we first investigated the postnatal development of morphological features and vocalizations in H. pomona based on mark-recapture data. Our aims were: (1) to measure the sizes of bat pups at birth, to derive age estimation equations based on length of forearm and the length of the total epiphyseal gap, and to compare the growth patterns of body mass and length of forearm using three non-linear equations; (2) to examine the origin of early echolocation calls and to investigate how the vocalizations of the young change with age.

\section{Materials and methods}

Study area

The study was conducted in an abandoned air-raid shelter (N 22 $2^{\circ} 7^{\prime}$, E $103^{\circ} 50^{\prime}$; ca. $250 \mathrm{~m}$ long, $2 \mathrm{~m}$ wide, and $2 \mathrm{~m}$ high) in Hekou County, Yunnan Province, China. This site had two entrances and housed a mixed colony of ca. 500 pomona leaf-nosed bats and 100 ashy leaf-nosed bats (Hipposideros cineraceus). The surrounding area was covered by dense forest of mostly rubber tree (Hevea brasiliensis) and banana tree (Musa nana).

Morphological measuring and acoustic recording

Based on prior investigation, we knew that the females of H. pomona gave birth in this area from mid-April to early May. Thus, from April 5, 2009, we checked the cave daily with lights for evidence of parturition. When newborn pups were observed (using morphological features to identify neonates of $H$. pomona), we captured neonates by hand following the nightly emergence of adults. We used an odorless marker to denote the locations from which we had captured neonates. Upon capture, young bats were placed in cloth holding bags and were transferred to a temporary laboratory $(5 \mathrm{~m} \times 4 \mathrm{~m} \times 3 \mathrm{~m})$ ca. $60 \mathrm{~m}$ from the roost site. After the sex of each pup was determined, a numbered alloy band (Porzana Ltd, UK) was placed on the forearm of each bat for individual identification. Neonates with an attached umbilical cord were assumed to be 1 day old (Kunz and Robson 1995). Body mass was recorded to the nearest $0.01 \mathrm{~g}$ using an electronic balance (ProScale LC-50, America). Length of forearm was measured to the nearest $0.01 \mathrm{~mm}$ with electronic vernier calipers (TESA-CAL IP67, Switzerland). The length of the total epiphyseal gap of the fourth metacarpal-phalangeal joint was measured to the nearest $0.01 \mathrm{~mm}$ using the calipers while the wing of the bat was spread out over a transparent solid plastic sheet illuminated from below with a strong torch to visualize the gap (Sharifi 2004a). To standardize potential error, all measurements were taken by the same person, and each measurement was made three times, from which an average was taken. After measurements were completed, calls from handheld bats were recorded with a condenser ultrasound microphone Avisoft Bioacoustics CM16 (Berlin, German) (the microphone was held $20-40 \mathrm{~cm}$ from each bat) and digitized through a PC laptop running Avisoft Recorder USG software (version 4.40, Avisoft Bioacoustics, Berlin, Germany). The sample rate was $500 \mathrm{kHz}$ at 16 bits resolution.

To limit disturbance and possible abandonment, measurement of morphological characters and recording of pups' calls took place while adults were out foraging and 
within a time frame of $1.5 \mathrm{~h}$ total. After measuring and recording, pups were returned to the site of original capture before females returned. The roost shelter was visited every 3 days (Table 1), and visits were made until the majority of the pups were volant and could no longer be captured, even with the aid of mist-nets and a hand-net by the end of midJune, 2009. Additionally, we mist-netted postpartum females at the shelter entrances and measured their body mass and length of forearm, and recorded their echolocation calls in late June 2009 for reference. All field work was conducted under license from local authorities.

\section{Data analysis}

We used the professional vocalization software Avisoft SASLab Pro (version 4.40, Berlin, Germany) to manually analyze calls. We chose $30-35$ calls with high signal-tonoise ratio from each bat on each visit day. For each call, we generated a spectrogram, a power spectrum, and an oscillogram. Spectrograms and power spectra were obtained by applying a fast Fourier transform (FFT) of 512 points and a Hamming window with $87.5 \%$ overlap. When the calls of the young were analyzed, a basic problem is how to define the precursors of echolocation calls (versus isolation calls). Based on some studies (Vater et al. 2003; Liu et al. 2007) and the development of vocalization in our study, the calls with constant frequencyfrequency modulated (CF-FM) structure and dominant frequency (DF) locating in the second harmonic were defined as early echolocation calls (others as isolation calls). For each isolation call, we considered the following variables: the frequency of maximum energy (i.e., DF) from the fundamental component, pulse duration (DT) and number of harmonics (NH). For each echolocation call, we measured the total duration of the CF-FM component (DT), the frequency of maximum energy (DF), and the bandwidth of the terminal frequency modulated (FM) from the second harmonic $\left(\mathrm{BFM}_{2}\right)$. The DF was measured from power spectra and pulse duration from oscillograms. The $\mathrm{NH}$ and $\mathrm{BFM}_{2}$ were taken from spectrograms. One-way analysis of variance was used to compare the difference of echolocation call parameters (DF, DT, and $\mathrm{BFM}_{2}$ ) between young at 40 -day age and adults.
We used an independent sample $t$ test to compare length of forearm and body mass of males and females at birth. Linear regression equations were derived to predict age from pooled data on forearm length (1-13 days) and the length of the total epiphyseal gap (10-40 days). To derive an age-predictive equation for the measurements, the axes on the growth curve were reversed and age for the specific periods were considered as the dependent variable (Kunz and Anthony 1982). Ninety-five percent confidence and prediction intervals were plotted for the regression equations for lengths of forearm and total epiphyseal gap. In addition, growth data of body mass and length of forearm in young bats were fitted to the three models: logistic, Gompertz, and von Bertalanffy equations (Table 2). The Levenberg-Marquardt algorithm was used to derive the best fit to the three non-linear equations. Results from the three different models were compared by the goodness of fit obtained from each model (Zullinger et al. 1984).

All statistical analysis was performed in SPSS 15.0 (SPSS Inc., Chicago, IL, USA), and data were described using means \pm SD unless stated otherwise.

\section{Results}

Each female observed produced a single pup. For 56 newborns with umbilical cord captured, no significant difference was found between length of forearm in males $(17.96 \pm 0.42 \mathrm{~mm})$ and females $(18.03 \pm 0.50 \mathrm{~mm}, t=0.5$, $d f=54, P>0.05$ ), although average forearm length of female was slightly longer. Similarly, body mass of male (2.31 $0.11 \mathrm{~g})$ and female $(2.36 \pm 0.12 \mathrm{~g})$ young was not significantly different $(t=1.6, d f=54, P>0.05)$. Length of forearm and body mass of newborns were $44.1 \%$ and $39.7 \%$ of that of adult females (length of forearm, $40.82 \pm$ $1.1 \mathrm{~mm}$; body mass, $5.89 \pm 0.6 \mathrm{~g}, n=31$ ), respectively.

Morphological development

Newborns were naked with a gray dorsal and a pink ventral part. They had closed eyes, folded ears, and deciduous teeth. Four days after birth, ears of the pups were raised partly with gray fur increasing in the dorsal part and gray fur becoming

Table 1 Number of individuals captured on day 1 and subsequently re-captured on other sampling occasions

\begin{tabular}{|c|c|c|c|c|c|c|c|c|c|c|c|c|c|c|}
\hline \multirow[t]{2}{*}{ Parameter } & \multicolumn{14}{|c|}{ Day of sampling } \\
\hline & 1 & 4 & 7 & 10 & 13 & 16 & 19 & 22 & 25 & 28 & 31 & 34 & 37 & 40 \\
\hline Number of re-captured bats & 56 & 32 & 26 & 25 & 29 & 25 & 28 & 28 & 18 & 14 & 12 & 9 & 8 & 6 \\
\hline Marked bats re-captured (\%) & - & 57 & 46 & 45 & 52 & 45 & 50 & 50 & 32 & 25 & 21 & 16 & 14 & 11 \\
\hline
\end{tabular}


Table 2 The three growth models were fitted in this paper

\begin{tabular}{ll}
\hline Model name & Model \\
\hline Logistic & $W=A(1+\exp (-K(t-I)))^{-1}$ \\
Gompertz & $W=A \exp (-\exp (-K(t-I)))$ \\
von Bertalanffy & $W=A(1-(1 / 3) \exp (-K(t-I)))^{3}$
\end{tabular}

The parameters $A$ and $K$ in each model were estimated for the growth of mass in the neonate population. Similar equations were used for length of forearm

$A$ is the asymptotic value (grams), $W$ is the body mass (grams) at age $t$ (days), $K$ is the growth rate constant $\left(\right.$ day $\left.^{-1}\right)$, and $I$ is the age at the inflection point (days)

visible in the ventral part. Eye slits appeared after 1 week, and the eyes were completely opened by 13 days. After 19 days, the young could fly awkwardly for a short distance when they were dropped from hands. After 31 days, most young bats could fly and turn agilely in the recording room, by which time the mean body mass and length of forearm were $4.94 \pm$ $0.25 \mathrm{~g}$ and $38.61 \pm 0.76 \mathrm{~mm}$, and they were $83.2 \%$ and $95.9 \%$ of adult values, respectively.

Empirical growth curves from 56 young based on changes in body mass, length of forearm, and the length of the total epiphyseal gap are shown in Fig. 1. During the first 13 days, body mass (Fig. 1a) and length of forearm (Fig. 1b) increased linearly with growth rates of $0.14 \mathrm{~g} / \mathrm{d}$ and $1.08 \mathrm{~mm} / \mathrm{d}$, respectively. Subsequently, the growth rates of these two characters decreased to a relatively constant value. Evaluation of coefficients of determination for the relationships between forearm length and age $\left(R^{2}=0.98\right)$ and between body mass and age $\left(R^{2}=0.93\right)$ indicated that length of forearm can be used to reliably estimate the age of young H. pomona up to 13 days of age, by which time average length of forearm was $30.6 \pm 0.76 \mathrm{~mm}$. Thus, the equation for estimating age from length of forearm is valid if this dimension is $\leq 30.6 \mathrm{~mm}$. The equation is as follows (Fig. 2a):

Age $($ days $)=0.92$ Forearm length

$$
-15.61\left(R^{2}=0.98, d f=167, P<0.05\right)
$$

In contrast, the length of the epiphyseal gap increased linearly until day 10 and then decreased linearly at a mean rate of $0.09 \mathrm{~mm} /$ day (Fig. 1c). At 10 days of age, length of forearm of pups was $27.84 \pm 0.7 \mathrm{~mm}$. A linear regression equation estimating the age was derived from the total length of the epiphyseal gap until day 40 . The equation is as follows (Fig. 2b):

$$
\begin{aligned}
\text { Age }(\text { days })= & -10.87 \text { Length of the total epiphyseal gap } \\
& +53.91\left(R^{2}=0.83, d f=201, P<0.05\right)
\end{aligned}
$$

Together, these two equations (i.e., Eqs. 1 and 2) allow us to predict the age of young $H$. pomona from 1 to 40 days after birth.

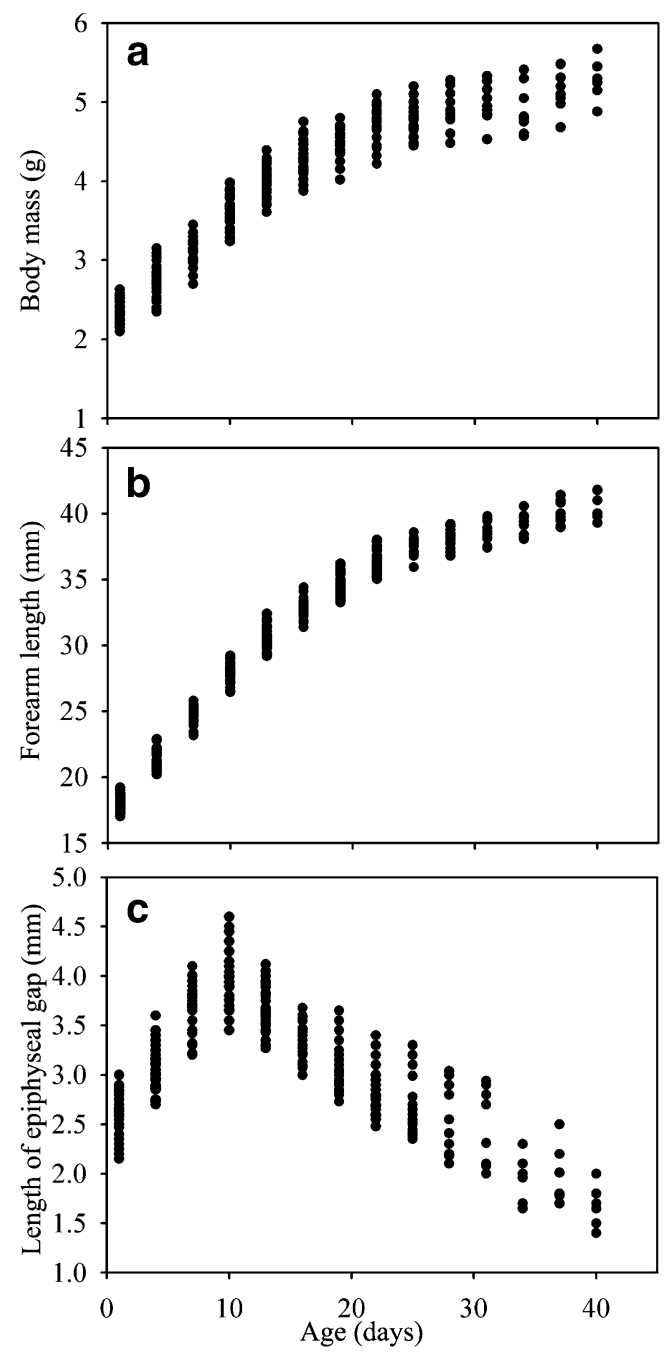

Fig. 1 Empirical growth curves for a body mass $(n=316)$, b length of forearm $(n=316)$, and $\mathbf{c}$ the length of the total gap of the fourth metacarpal-phalangeal joint $(n=316)$ of young H. pomona from day 1 to 40 . Some points represent more than one observation

The logistic, Gompertz and von Bertalanffy models gave a good fit to the changes in length of forearm and body mass. A summary of growth parameters derived from the three non-linear growth models is given in Table 3. Based on the sum of squares model, the logistic model appeared to provide the best fit for body mass and length of forearm (Table 3).

Vocalization development with age

Newborn $H$. pomona were usually silent and only sporadically emitted multiple harmonic calls with fundamental frequencies usually above $20 \mathrm{kHz}$. As the pups grew older, they vocalized more actively.

During the first 4 days, young bats emitted signals with various structures, including upward sweep to constant frequency (CF; 11-14 ms; Fig. 3a), noisy quasi-CF (QCF; 

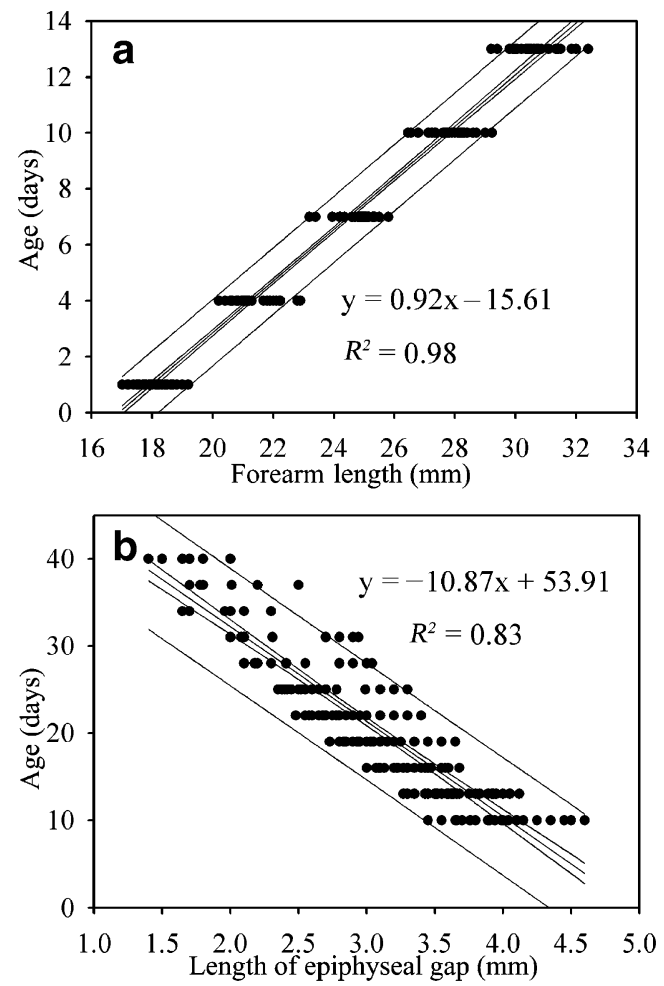

Fig. 2 Regression line estimating the age of H. pomona from a the values of length of forearm up to 13 days, and $\mathbf{b}$ the values of epiphyseal gap length at 10-40 days. Some points represent more than one observation. The predictive equation is valid for length of forearm $\leq 30.6 \mathrm{~mm}$ and $>30.6 \mathrm{~mm}$, respectively. Narrow and wide bands indicate $95 \%$ confidence and prediction intervals, respectively. Age $($ days $)=0.92 \times$ length of forearm $-15.61 \quad\left(R^{2}=0.98, d f=167\right.$, $P<0.05)$ and age (days) $=-10.87 \times$ length of epiphyseal gap +53.91 $\left(R^{2}=0.83, d f=201, P<0.05\right)$, respectively

9-12 ms; Fig. 3b), downward FM sweeps (7-10 ms; Fig. 3c), short (7-10 ms) and long (13-18 ms) QCF (Fig. 3d), CF-FM (7-11 ms; Fig. 3e) and short CF (4-9 ms; Fig. 3f). Those CF-FM calls contained up to seven harmonics with most energy concentrating on the fundamental frequency (Fig. 3e) and they did not develop into echolocation calls during the later postnatal growth (Fig. 4a-d, g). Thus, these calls mentioned above were all isolation calls. Based on the definition of the early echolocation calls as mentioned previously (see section "Materials and methods"), we did not distinguish the precursors of echolocation calls until the seventh day in three young bats, but they were faint in energy and were comprised of only four components (Fig. $4 \mathrm{e}-\mathrm{h}$ ).

Isolation calls and early echolocation calls changed in their frequency/time structure with the age of the growing bat (Figs. 5 and 6). Specifically, isolation calls were usually multi-harmonic. Typically, the first harmonic was the most intense and other harmonic energy decreased accordingly. The number of harmonics decreased (Fig. 4a-d) and DF increased (Fig. 5). However, the duration of isolation calls remained relatively stable (Fig. 6). Interestingly, during 1928 days after birth, except for some short isolation calls, some distinct longer isolation calls (the maximum duration up to $75 \mathrm{~ms}$ ) were recorded when the young were handheld, mainly including W-shaped FM (Fig. 7a), QCF-FM (Fig. 7b), QCF (Fig. 7c), and downward FM (Fig. 7d). After 28 days of age, young bats that were handheld seldom emitted isolation calls, although they occasionally produced some calls like distress calls of adults emitted from the mouth. However, in the roost shelter, young bats still produced isolation calls when female adults approached them even after 4 weeks.

Early echolocation calls typically contained four harmonics, and the second harmonic was usually the most intense. With the development of young bats, the first and fourth harmonics disappeared, but the second and third harmonics remained (Fig. 4e-h). Additionally, the DF of echolocation calls increased quickly during the second week and thereafter increased slowly (Fig. 5). From 7 days

Table 3 Growth parameters in H. pomona, derived from the logistic, Gompertz, and von Bertalanffy growth models

\begin{tabular}{|c|c|c|c|c|c|c|c|c|c|}
\hline \multirow[b]{2}{*}{ Growth model } & \multirow[b]{2}{*}{ Parameter } & \multicolumn{4}{|c|}{ Body mass versus age } & \multicolumn{4}{|c|}{ Length of forearm versus age } \\
\hline & & Estimate & SE & $\mathrm{CV}(\%)$ & MSS & Estimate & SE & CV (\%) & MSS \\
\hline \multirow[t]{3}{*}{ Logistic } & A & 5.17 & 0.041 & 0.79 & \multirow[t]{3}{*}{13.22} & 40.68 & 0.153 & 0.38 & \multirow[t]{3}{*}{156.32} \\
\hline & $\mathrm{K}$ & 0.12 & 0.004 & 3.42 & & 0.11 & 0.002 & 1.82 & \\
\hline & I & 2.88 & 0.174 & 6.04 & & 3.09 & 0.084 & 2.72 & \\
\hline \multirow[t]{3}{*}{ Gompertz } & A & 5.31 & 0.053 & 1.00 & \multirow[t]{3}{*}{13.62} & 41.81 & 0.197 & 0.47 & \multirow[t]{3}{*}{159.14} \\
\hline & $\mathrm{K}$ & 0.09 & 0.003 & 3.41 & & 0.08 & 0.001 & 1.20 & \\
\hline & I & -0.96 & 0.159 & -16.65 & & -0.94 & 0.073 & -7.76 & \\
\hline \multirow[t]{3}{*}{ von Bertalanffy } & A & 5.37 & 0.059 & 1.10 & \multirow[t]{3}{*}{13.84} & 42.34 & 0.223 & 0.53 & \multirow[t]{3}{*}{164.62} \\
\hline & $\mathrm{K}$ & 0.08 & 0.003 & 3.85 & & 0.07 & 0.001 & 1.35 & \\
\hline & I & -2.75 & 0.182 & -6.61 & & -2.84 & 0.082 & -2.89 & \\
\hline
\end{tabular}

Note: $A$ asymptotic size of forearm length (centimeters) or body mass (grams), $K$ growth rate constant, $I$ inflection point, $S E$ is standard error, $C V$ is coefficient of variation, MSS is model sum of squares 


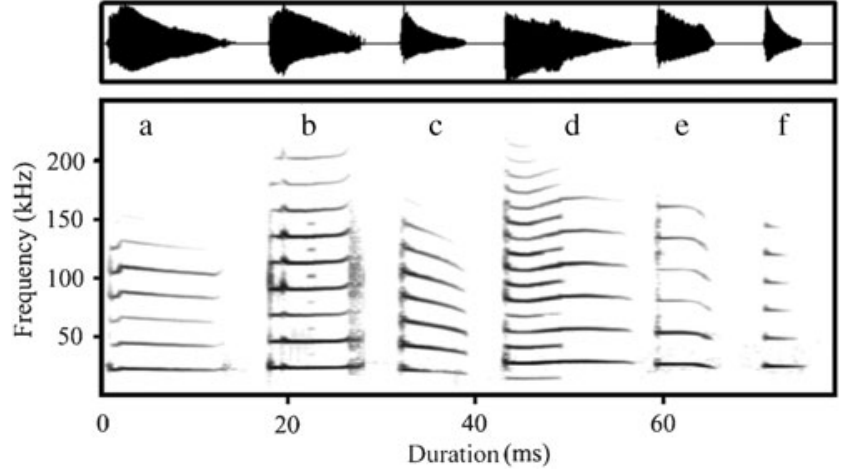

Fig. 3 Vocal repertoire of infant $H$. pomona during the first 4 days. Top of each graph presents oscillogram and bottom presents spectrogram of respective calls. a upward sweep to CF, b noisy QCF, $\mathbf{c}$ downward FM, $\mathbf{d}$ short and long QCF, e CF-FM, and $\mathbf{f}$ short CF. All spectrograms were produced using a 512-point FFT and a Hamming window with $87.5 \%$ overlap

to 40 days, the $\mathrm{BFM}_{2}$ increased (Fig. 5) and the duration decreased (Fig. 6). By day 40, there was significant difference in DF $\left(F_{1}, 35=33.83, P<0.05\right)$ between the young and adult calls (DF, $126.6 \pm 0.68 \mathrm{kHz}$ ). However, there was no significant difference in $\mathrm{BFM}_{2}$ (adult, 21.33 \pm $1.76 \mathrm{kHz}, F_{1,35}=3.81, P>0.05$ ) and duration (adult, $5.78 \pm$ $\left.0.52 \mathrm{~ms} ; F_{1,35}=2.59, P>0.05\right)$.

\section{Discussion}

For newborn H. pomona in the present study, we found no significant differences between males and females both in body mass and length of forearm, which was consistent with studies on Hipposideros terasensis (Cheng et al. 2002) and Tadarida brasiliensis mexicana (Kunz and Robson 1995). However, a significant difference in body mass existed among that of Artibeus watsoni (Chaverri and Kunz 2006). Additionally, body mass of neonates are $11-43 \%$ of

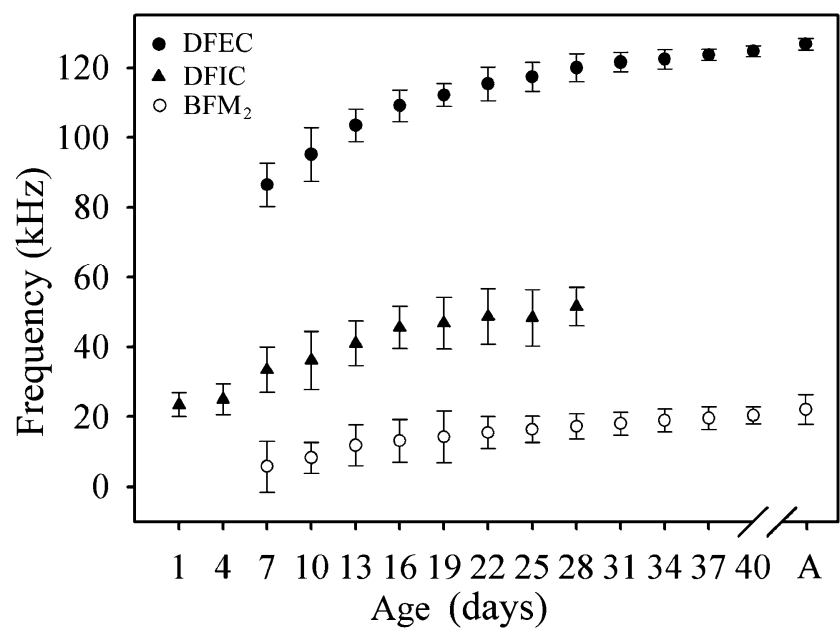

Fig. 5 Changes of the mean values of dominant frequency of echolocation calls (DFEC) and isolation calls (DFIC), and bandwidth of the terminal $\mathrm{FM}_{2}\left(\mathrm{BFM}_{2}\right)$ with age during the growth of young in H. pomona. A represents adults and error bar represents $2 \mathrm{SD}$

that of adults (Altringham 1996; Kunz et al. 2009). In this study, the mean mass at birth of neonates of H. pomona was relatively large (39.7\% of that of adults), which is generally associated with an advanced stage of development and is believed to aid the conservation of heat generated to maintain constant body temperature when the mother leaves the roost to forage (Reiter 2004). Carrying a heavier fetus during pregnancy and the associated increase in wing loading, however, can reduce flight maneuverability of pregnant females, which may, in turn, have increased predation risks from raptorial birds (McLean and Speakman 2000). Whereas, interestingly, after 2 weeks, some $H$. pomona females occasionally carried their young during foraging bouts even when they were large in size (body mass of young bats were ca. $65 \%$ of that of adults by that time) in our study (Long-ru Jin, personal observation), which suggested that $H$. pomona has a good flight ability

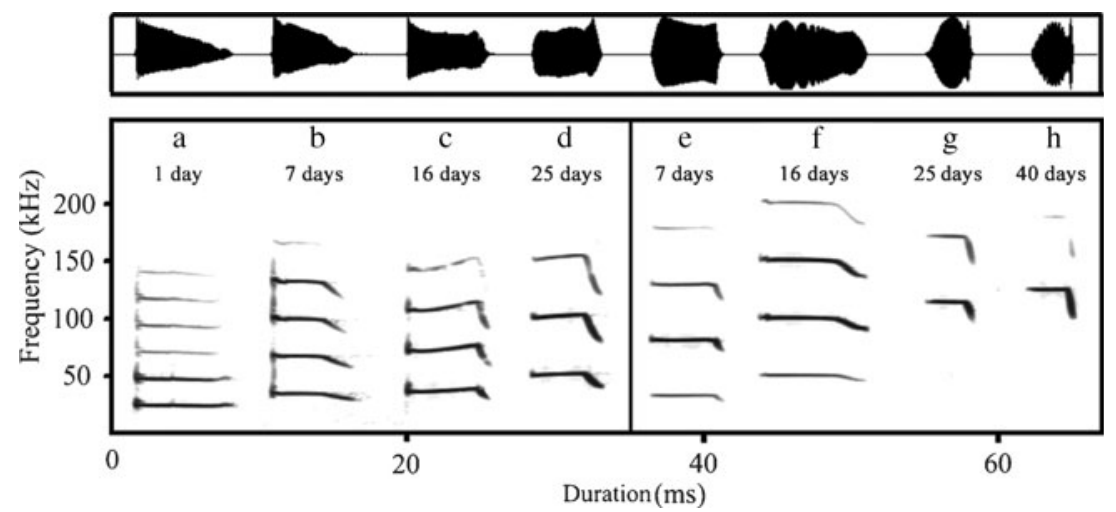

Fig. 4 Modification of the isolation call (left, a-d) and echolocation call (right, $\mathbf{e}-\mathbf{h}$ ) with age. Top of each graph presents oscillogram and bottom presents spectrogram of respective calls. Oscillograms and sonograms of the isolation calls produced by the same infant of $H$. pomona aged 1 (a), 7 (b), 16 (c), and 25 (d) days; oscillograms and sonograms of the echolocation calls produced by the same infant of $H$. pomona aged 7 (e), 16 (f), 25 (g), and 40 (d) days 


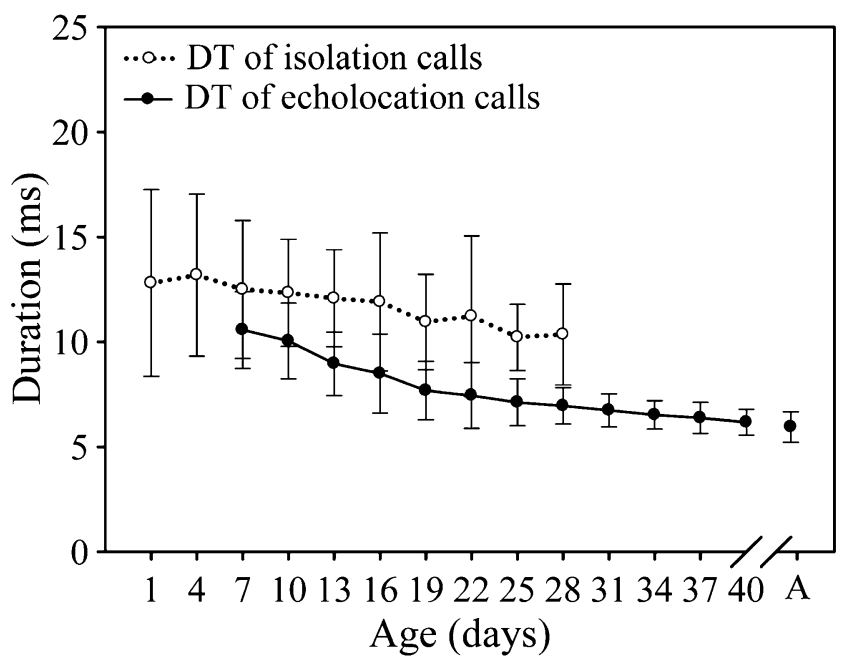

Fig. 6 Changes of the mean values of pulse duration of isolation calls and echolocation calls with age during growth of young in $H$. pomona. A represents adults and error bar represents $1 \mathrm{SD}$

and that their forage area is close to their roost site, and it might indicate that their predators are scarce in this area.

\section{Morphological development}

The characteristics of neonates in $H$. pomona, including closed eyes, folded ears, and deciduous teeth, were similar to those of most other bat species. However, the neonates have gray dorsal part, and their eyes fully opened late, which is different from those of most other species (e.g., Pipistrellus mimus-Isaac and Marimuthu 1996; Myotis blythii-Sharifi 2004b) except $H$. terasensis (Cheng et al. 2002), and Hipposideros sperois (Habersetzer and Marimuthu 1986). Additionally, we also observed that $H$. cineraceus and Hipposideros larvatus pups had characteristics in common with $H$. pomona. Thus, the possibility that this is a phenomenon common to the Hipposideridae bats invites further investigation.

Sustained flight of young $H$. pomona occurred in a 31day-old, by which time they had achieved $83.2 \%$ of adult body mass and $95.9 \%$ of adult forearm proportions. This is similar to juveniles of other microchiropterans, which typically begin to fly when they attain $70 \%$ of adult body mass and $90 \%$ of adult forearm length (Kunz and Robson 1995; Kunz and Hood 2000; Kunz et al. 2009). Having a small body size and a larger skeletal size at the onset of flight would result in a lower wing loading and, in turn, would contribute to increased maneuverability and decreased the cost of flight, which is important for the survival of young bat (Hughes et al. 1995). Additionally, in some bat species, the young would experience a loss of body mass during the early flight and weaning period and such reduction in body mass may reflect the poor foraging ability (Sharifi 2004a). However, the phenomenon of temporary reduction in body mass was not reported in development of other bat species (e.g., M. blythii-Sharifi 2004b; Myotis formosus-Shen and Lee 2000). In our study, the changes of body mass were similar to the latter phenomenon.

Although body mass also increased linearly in the early postnatal growth, the coefficient was lower than that between length of forearm and age. Thus, age estimation of young bats should be based on length of forearm and the length of the total epiphyseal gap, which is consistent with other studies (Hood et al. 2002; Sharifi 2004a; Kunz et al. 2009). However, on the other hand, postnatal growth rates in bats are influenced by climate, food supply, roost temperature, latitude, maternal factors, colony size, and anthropogenic factors (Allen et al. 2009; Kunz et al. 2009), which might limit the application of growth equations to their general areas of origin. Thus, as suggested by Kunz et al. (2009), we encourage researchers to compare the changes in different years and to generate geographically specific equations whenever possible.

Of the three non-linear growth models, the logistic model best described growth rates for length of forearm and body mass in free-ranging $H$. pomona. Similar conclusions were made for Pipistrellus pipistrellus (Hughes et al. 1995), Plecotus auritus (De Fanis and Jones 1995), and T. brasiliensis mexicana (Kunz and Robson 1995). However, in other studies (e.g., Kunz 1974), the von Bertalanffy model gave the best fit for body mass. Given the relatively few studies that have compared different models, the general significance of these differences remains unclear. In addition, on the basis of reviews by

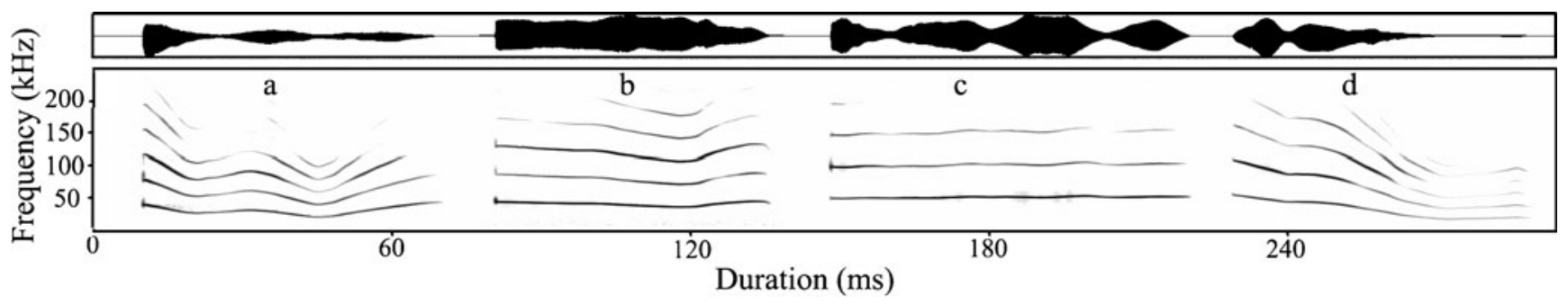

Fig. 7 Vocal repertoire with distinct characteristics produced by different young H. pomona bats between 19-28 days. a 19 day old, b 22 day old, c 25 day old, and $\mathbf{d} 28$ day old 
Kunz and Hood (2000), growth constant rates of body mass of all tropical microchiropterans were 0.04-0.11 $(n=11)$, and the rates of most temperate microchiropteran species were $0.12-0.25(n=13)$. In our study, the constant rate of body mass was 0.12 , which embodied the regional features (i.e., a transition zone between subtropical and tropical environments).

\section{Vocal development of young bats}

During the first 4 days, the pups of $H$. pomona emitted various structure signals, which were also seen in the studies of Rhinolophus ferrumequinum (Liu et al. 2007) and P. parnellii (Vater et al. 2003). On the basis of call characteristics, they were identified as isolation calls. During ontogeny in $H$. pomona, early echolocation calls increased in DF and decreased in number of harmonics until they resembled adult's echolocation calls. Thus, we inferred that early echolocation calls in H. pomona did not originate from isolation calls, but developed independently, which is consistent with the studies on $N$. albiventris (Brown et al. 1983), P. pipistrellus (Jones et al. 1991), P. parnellii (Vater et al. 2003), and R. ferrumequinum (Liu et al. 2007). However, in other studies (e.g., P. auritus-De Fanis and Jones 1995; M. lucifugus-Moss et al. 1997; C. perspicillata-Sterbing 2002), echolocation calls develop from communication calls by a continuous change in signal parameters, such as duration, frequency content, modulation rate, and harmonic content.

Newborn $H$. pomona always emitted isolation calls of the same relatively high fundamental frequency $(>20 \mathrm{kHz})$ with the maximum energy as Hipposideros speoris (Habersetzer and Marimuthu 1986), but neonates of larger-sized rhinolophids use lower frequencies $(<20 \mathrm{kHz}$; e.g., R. ferrumequinum-Matsumura 1979; Rhinolophus rouxi-Rübsamen 1987). In previous studies, the dominant frequency of echolocation calls is was negatively correlated with body size (Francis and Habersetzer 1998). Considering both echolocation and isolation calls emitted through vocal tract, we inferred that those differences among fundamental frequencies might result from differences in body size.

Previously studies have shown that the developmental trend of isolation calls in bats generally falls into two categories: (1) increasing in DF, decreasing in number of harmonics and duration (e.g., Jones et al. 1991; Zhang et al. 2005); or (2) remaining stable in structure throughout the lactation period (e.g., Parijs and Corkeron 2002). Our results for $H$. pomona were generally similar to the former. Additionally, the duration of isolation calls remained relatively stable. This was unexpected and awaits further investigation. During 19-28 days, some individuals emitted long duration isolation calls (Fig. 7). Given low sample size, these long calls were excluded from our statistical analysis.
For early echolocation calls, the $\mathrm{DF}$ and $\mathrm{BFM}_{2}$ of echolocation calls both increased, which may involve maturation at the effector (laryngeal muscles, cartilage stiffness, tendons) and at the level of central neuronal control (Vater et al. 2003). For CF-FM echolocating bats, the $\mathrm{CF}$ portion is used to evaluate relative motion, whereas the terminal downward FM is used to determine target distance. Thus, a higher CF may help detect moving targets and a wider bandwidth may convey more target-specific and higher resolution information, which is advantageous for spatial orientation during hunting and target capture by young bats. The duration of echolocation calls in juvenile $H$. pomona decreased until it resembled that of adults, which is similar to H. speoris (Habersetzer and Marimuthu 1986). However, in the studies on R. ferrumequinum (Liu et al. 2007) and P. parnellii (Vater et al. 2003), the duration of echolocation calls increased as juveniles matured.

When young bats began to forage, there was a significant difference in DF of echolocation calls compared with those of adults. This difference is also found in other studies (Buchler 1980; Jones and Ransome 1993; Chen et al. 2009). Wund (2005) suggested that young bats may learn to modify their echolocation calls to enhance performance once they have begun to forage. Thus, we inferred that young $H$. pomona would increase the DF of echolocation calls when they begin to forage and gain experience in a new habitat.

Acknowledgements This study was financed by the National Natural Science Foundation of China (Grant No. 30870371, 30900166, 31030011) and the National Grand Fundamental Research 973 Program of China (2009CB426305). We thank Zheng Liu and his family for their invaluable field assistance. We thank Thomas H. Kunz, Kirsten M. Bohn, and one anonymous reviewer for their constructive comments on earlier versions of the manuscript. We declare that we have no conflict of interest. The experiments on bats complied with ethical standards in the treatment of them.

\section{References}

Allen LC, Richardson CS, McCracken GF, Kunz TH (2009) Birth size and postnatal growth in cave- and bridge-roosting Brazilian freetailed bats. J Zool Lond 280:8-16. doi:10.1111/j.14697998.2009.00636.x

Altringham JD (1996) Bats: biology and behaviour. Oxford University Press, London

Anthony ELP (1988) Age determination in bats. In: Kunz TH (ed) Ecological and behavioral methods for the study of bats. Smithsonian Institution Press, Washington, pp 47-58

Baptista TL, Richardson CS, Kunz TH (2000) Postnatal growth and age estimation in free-ranging bats: a comparison of longitudinal and cross-sectional sampling methods. J Mammal 81:709-718. doi:10.1644/1545-1542(2000)081<0709:pgaaei $>2.3$.co;2

Brown PE, Grinnell AD (1980) Echolocation ontogeny in bats. In: Busnell RG, Fish JF (eds) Animal sonar systems. Plenum Press, New York, pp 355-377 
Brown PE, Brown TW, Grinnell AD (1983) Echolocation, development, and vocal communication in the lesser bulldog bat, Noctilio albiventris. Behav Ecol Sociobiol 13:287-298. doi:10.1007/bf00299676

Brunet-Rossinni AK, Wilkinson GS (2009) Methods for age estimation and the study of senescence in bats. In: Kunz TH, Parsons S (eds) Ecological and behavioral methods for the study of bats, 2nd edn. Johns Hopkins University Press, Baltimore, pp 315-325

Buchler ER (1980) The development of flight, foraging, and echolocation in the little brown bat (Myotis lucifugus). Behav Ecol Sociobiol 6:211-218. doi:10.1007/bf00569202

Chaverri G, Kunz TH (2006) Reproductive biology and postnatal development in the tent-making bat Artibeus watsoni (Chiroptera: Phyllostomidae). J Zool Lond 270:650-656. doi:10.1111/ j.1469-7998.2006.00171.x

Chen SF, Jones G, Rossiter SJ (2009) Determinants of echolocation call frequency variation in the Formosan lesser horseshoe bat (Rhinolophus monoceros). P Roy Soc Lond B Bio 276:39013909. doi:10.1098/rspb.2009.1185

Cheng HC, Lee LL, Gannon WL (2002) Postnatal growth, age estimation, and sexual maturity in the Formosan leaf-nosed bat (Hipposideros terasensis). J Mammal 83:785-793. doi:10.1644/ 1545-1542(2002)083<0785:pgaeas $>2.0 . c 0 ; 2$

De Fanis E, Jones G (1995) Postnatal growth, mother-infant interactions and development of vocalizations in the vespertilionid bat Plecotus auritus. J Zool Lond 235:85-97

Elangovan V, Priya EYS, Raghuram H, Marimuthu G (2003) Postnatal development in the Indian short-nosed fruit bat Cynopterus sphinx: growth rate and age estimation. Acta Chiroptero 5:107-116

Francis CM, Habersetzer J (1998) Interspecific and intraspecific variation in echolocation call frequency and morphology of horseshoe bats, Rhinolophus and Hipposideros. In: Kunz TH, Racey PA (eds) Bats: biology and conservation. Smithsonian Institution Press, Washington, pp 169-179

Frick WF, Reynolds DS, Kunz TH (2010) Influence of climate and reproductive timing on demography of little brown myotis Myotis lucifugus. J Anim Ecol 79:128-136. doi:10.1111/j.13652656.2009.01615.x

Gould E (1971) Studies of maternal-infant communication and development of vocalizations in the bats Myotis and Eptesicus. Commun Behav Biol 5:263-313

Gould E, Woolf NK, Turner DC (1973) Double-note communication calls in bats: occurrence in three families. J Mammal 54:998 1001. doi: $10.2307 / 1379103$

Habersetzer J, Marimuthu G (1986) Ontogeny of sounds in the echolocating bat Hipposideros speoris. J Comp Physiol A 158:247-257

Hood WR, Bloss J, Kunz TH (2002) Intrinsic and extrinsic sources of variation in size at birth and rates of postnatal growth in the big brown bat Eptesicus fuscus (Chiroptera: Vespertilionidae). J Zool Lond 258:355-363. doi:10.1017/s0952836902001504

Hoying KM, Kunz TH (1998) Variation in size at birth and postnatal growth in the insectivorous bat Pipistrellus subflavus (Chiroptera: Vespertilionidae). J Zool Lond 245:15-27

Hughes PM, Rayner JMV, Jones G (1995) Ontogeny of "true" flight and other aspects of growth in the bat Pipistrellus pipistrellus. J Zool Lond 236:291-318. doi:10.1111/j.1469-7998.1995.tb04494.x

Isaac SS, Marimuthu G (1996) Postnatal growth and age estimation in the Indian pygmy bat Pipistrellus mimus. J Mammal 77:199-204. doi: $10.2307 / 1382721$

Jones G, Ransome RD (1993) Echolocation calls of bats are influenced by maternal effects and change over a lifetime. P Roy Soc Lond B 252:125-128. doi:10.1098/rspb.1993.0055

Jones G, Hughes PM, Rayner JMV (1991) The development of vocalizations in Pipistrellus pipistrellus (Chiroptera: Vespertilionidae) during postnatal growth and the maintenance of individual vocal signatures. J Zool Lond 225:71-84. doi:10.1111/j.14697998.1991.tb03802.x

Knörnschild M, Von Helversen O, Mayer F (2007) Twin siblings sound alike: isolation call variation in the noctule bat, Nyctalus noctula. Anim Behav 74:1055-1063. doi:10.1016/j. anbehav.2006.12.024

Kunz TH (1974) Reproduction, growth, and mortality of the vespertilionid bat, Eptesicus fuscus, in Kansas. J Mammal 55:1-13. doi:10.2307/1379252

Kunz TH, Anthony ELP (1982) Age estimation and postnatal growth in the bat Myotis lucifugus. J Mammal 63:23-32

Kunz TH, Robson SK (1995) Postnatal growth and development in the Mexican free-tailed bat (Tadarida brasiliensis mexicana): birth size, growth rates, and age estimation. J Mammal 76:769783. doi: $10.2307 / 1382746$

Kunz TH, Hood WR, Crichton EG, Krutzsch PH (2000) Parental care and postnatal growth in the Chiroptera. In: Reproductive biology of bats. Academic, London, pp 415-468. doi:10.1016/b978012195670-7/50011-4

Kunz TH, Adams RA, Hood WR (2009) Methods for assessing postnatal growth and development of bats. In: Kunz TH, Parsons $\mathrm{S}$ (eds) Ecological and behavioral methods for the study of bats, 2nd edn. Johns Hopkins University Press, Baltimore, pp 273-324

Kurta A, Kunz TH (1987) Size of bats at birth and maternal investment during pregnancy. In: Racey PA, Loudon A (eds) Reproductive energetic of mammals. Oxford University Press, London, pp 79-106

Liu Y, Feng J, Jiang YL, Wu L, Sun KP (2007) Vocalization development of greater horseshoe bat, Rhinolophus ferrumequinum (Rhinolophidae, Chiroptera). Folia Zool 56:126-136

Liu Y, Jin LR, Metzner W, Feng J (2009) Postnatal growth and age estimation in big-footed myotis, Myotis macrodactylus. Acta Chiroptero 11:105-111. doi:10.3161/150811009x465721

Matsumura S (1979) Mother-infant communication in a horseshoe bat (Rhinolophus ferrumequinum nippon): development of vocalization. J Mammal 60:76-84. doi:10.2307/1379760

McLean JA, Speakman JR (2000) Morphological changes during postnatal growth and reproduction in the brown long-eared bat Plecotus auritus: implications for wing loading and predicted flight performance. J Nat Hist 34:773-791

Moss CF, Redish D, Gounden C, Kunz TH (1997) Ontogeny of vocal signals in the little brown bat, Myotis lucifugus. Anim Behav 54:131-141. doi:10.1006/anbe.1996.0410

Parijs SMV, Corkeron PJ (2002) Ontogeny of vocalisations in infant black flying foxes, Pteropus alecto. Behaviour 139:1111-1124

Rajan KE, Marimuthu G (1999) Postnatal growth and age estimation in the Indian false vampire bat (Megaderma lyra). J Zool Lond 248:529-534. doi:10.1111/j.1469-7998.1999.tb01052.x

Reiter G (2004) Postnatal growth and reproductive biology of Rhinolophus hipposideros (Chiroptera: Rhinolophidae). J Zool Lond 262:231-241. doi:10.1017/s0952836903004588

Rübsamen R (1987) Ontogenesis of the echolocation system in the rufous horseshoe bat, Rhinolophus rouxi (audition and vocalization in early postnatal development). J Comp Physiol A 161:899913. doi:10.1007/bf00610231

Sharifi M (2004a) Postnatal growth and age estimation in the Mehelys horseshoe bat (Rhinolophus mehelyi). Acta Chiroptero 6:155-161

Sharifi M (2004b) Postnatal growth in Myotis blythii (Chiroptera, Vespertilionidae). Mammalia 68:283-289. doi:10.1515/ mamm.2004.027

Shen HP, Lee LL (2000) Mother-young interactions in a maternity colony of Myotis formosus. J Mammal 81:726-733. doi:10.1644/ 1545-1542(2000)081<0726:myiiam>2.3.co;2

Simmons NB (2005) Order Chiroptera. In: Wilson DE, Reeder DM (eds) Mammal species of the world: a taxonomic and geographic reference, 3rd edn. Johns Hopkins University Press, Baltimore, pp 312-529 
Sterbing SJ (2002) Postnatal development of vocalizations and hearing in the phyllostomid bat, Carollia perspicillata. J Mammal 83:516-525. doi:10.1644/1545-1542(2002)083<0516: pdovah>2.0.co;2

Stern AA, Kunz TH (1998) Intraspecific variation in postnatal growth in the greater spear-nosed bat. J Mammal 79:755-763. doi: $10.2307 / 1383086$

Vater M, Kossl M, Foeller E, Coro F, Mora E, Russell IJ (2003) Development of echolocation calls in the mustached bat, Pteronotus parnellii. J Neurophysiol 90:2274-2290. doi:10.1152/jn.00101.2003
Wund MA (2005) Learning and the development of habitatspecific bat echolocation. Anim Behav 70:441-450. doi:10.1016/j.anbehav.2004.11.009

Zhang LB, Jones G, Parsons S, Liang B, Zhang SY (2005) Development of vocalizations in the flat-headed bats, Tylonycteris pachypus and T. robustula (Chiroptera: Vespertilionidae). Acta Chiroptero 7:91-99. doi:10.3161/1733-5329(2005)7[91: dovitf]2.0.co; 2

Zullinger EM, Ricklefs RE, Redford KH, Mace GM (1984) Fitting sigmoidal equations to mammalian growth curves. J Mammal 65:607-636. doi:10.2307/1380844 